\title{
Profesoras en medio de la violencia armada: una pedagogía visceral desde las favelas de Rio de Janeiro*
}

DOI: https://doi.org/10.18046/recs.i33.4106

\author{
Teaching in the Midst of Armed Violence: A Visceral Pedagogy \\ from the Favelas of Rio de Janeiro
}

\author{
Alanis Bello-Ramírez ${ }^{* *}$ \\ Universidade de São Paulo (San Pablo, Brasil) \\ Cláudia Pereira-Vianna ${ }^{* * *}$ \\ Universidade de São Paulo (San Pablo, Brasil)
}

\begin{abstract}
* El presente artículo surge de la tesis doctoral titulada No coração da guerra: memórias e práticas de cuidado de professoras em contextos de violência armada, desarrollada en la línea de investigación de Sociología de la Educación de la Facultad de Educación (Universidad de São Paulo). Esta investigación se encuentra en un período de ejecución parcial y fue financiada por el Programa de Estudiantes-Convênio de Pós-Graduação (PEC-PG), de la agencia CAPES (Brasil). Artículo de investigación recibido el 22.06.20 y aceptado el 03.01.21.

** Magíster en Estudios de Género de la Universidad Nacional de Colombia (Colombia); estudiante del Doctorado en Educación de la Universidad de São Paulo (Brasil); becaria colombiana del PEC-PG (CAPES, Brasil), e investigadora del Grupo Interdisciplinario de Estudios de Género (GIEG), de la Universidad Nacional de Colombia (Colombia). Correo electrónico: alanisbr@usp.br ORCID: https://orcid.org/0000-0001-9956-4364

*** Doctora en Educación de la Universidad de São Paulo (Brasil); posdoctora en Educación de la Universidad Autónoma de Madrid (España); profesora asociada senior de la Facultad de Educación de la Universidad de São Paulo (Brasil), y coordinadora del Grupo de Estudos de Gênero, Educação e Cultura Sexual (Universidad de São Paulo (Brasil) - Conselho Nacional de Desenvolvimento Científico e Tecnológico). Correo electrónico: cpvianna@usp.br ORCID: https://orcid. org/0000-0002-9366-4417
\end{abstract}




\section{Cómo citar/How to cite}

Bello-Ramírez, Alanis; Pereira-Vianna, Cláudia (2021). Profesoras en medio de la violencia armada: una pedagogía visceral desde las favelas de Rio de Janeiro. Revista CS, 33, 11-40. https://doi.org/10.18046/recs.i33.4106 


\section{Resumen}

¿Qué pueden hacer las escuelas y los docentes para mitigar los impactos de la violencia armada? Comenzando en esta pregunta, se presentan las experiencias de profesoras negras que trabajan en escuelas afectadas por la violencia armada en las favelas de Rio de Janeiro. Se reconoce el cuidado y el trabajo emocional como elementos fundamentales para enfrentar la violencia e imaginar otros futuros. A partir de la información obtenida de entrevistas en profundidad, observación etnográfica y talleres pedagógicos, se analizan las condiciones de trabajo de las docentes y el impacto que ha tenido la violencia armada y el racismo sobre las escuelas de las favelas. Por último, se propone la noción de pedagogía visceral para comprender los esfuerzos pedagógicos que hacen las profesoras para mantener la vida en un contexto de extrema vulnerabilidad.

\section{PALABRAS CLAVE:}

cuidado, violencia armada, racismo, profesoras, favelas

What can schools and teachers do to mitigate the consequences of armed violence? Based on this question, the experiences of black teachers working in schools affected by the armed violence in the favelas of Rio de Janeiro are narrated. Care and emotional work are recognized as fundamental elements to face this situation and imagine other futures. With the information gathered from in-depth interviews, ethnographic observation, and pedagogical workshops, we analyzed the teachers' working conditions and the impact that armed violence and racism has had on the schools in the favelas. Finally, the notion of visceral pedagogy is proposed to understand the pedagogical efforts that teachers make to maintain life in a context of extreme vulnerability.

\section{KEYWORDS:}

Care, Armed Violence, Racism, Teacher, Favela 



\section{Introducción}

En este artículo nos interesa explorar el trabajo pedagógico desarrollado por profesoras en escuelas afectadas por la violencia armada en las favelas de la zona norte de Rio de Janeiro. En esta exploración, buscamos comprender cómo la incorporación de una ética del cuidado y un trabajo emocional en las prácticas docentes potencializa la construcción de espacios educativos para subvertir la violencia armada, proyectar posibilidades de futuro y crear lazos afectivos para la sanación. En el fondo, nos interesa entender el complejo trabajo de configurar mundos y devenir con otros, en contextos dañados por la muerte y la destrucción. En sintonía con Haraway (2019: 68), buscamos desenrollar los hilos de una pedagogía del cuidado como base para potenciar la vida en medio de las ruinas que produce la violencia.

El escenario de violencia en el que analizamos el trabajo pedagógico de las profesoras se encuentra en algunas de las favelas de Rio de Janeiro, Brasil. A partir de la década de 1990, las favelas cariocas se convirtieron en un escenario bélico donde el Estado brasilero desplegó una agresiva estrategia de militarización para combatir un fenómeno de criminalidad creciente que vincula a bandas de narcotráfico y facciones criminales. Este proceso ha desencadenado graves violaciones a los derechos humanos de los habitantes de las favelas, y el despliegue de una política de seguridad pautada en la segregación territorial, la estigmatización y la muerte (Farias, 2007; Oliveira, 2014).

En el campo de la investigación educativa, hay una considerable evidencia de los daños que dicho conflicto ha generado en el sistema educativo público de la ciudad. Entre los más visibles, se encuentran el cierre de escuelas y guarderías debido a las constantes operaciones militares, la destrucción de los entornos de aprendizaje, y el bajo logro educativo de niños, niñas y jóvenes favelados ${ }^{1}$ por cuenta de las afectaciones propias de la violencia armada (Burgos, 2009; Muniz, 2019; Plataforma DhESCA, 2008).

La violencia armada es nociva para la práctica educativa. Como apunta la antropóloga Rita Segato (2018), la repetición de la violencia produce un efecto de crueldad en la manera de construir relaciones de alteridad, pues promueve en los individuos bajos umbrales de empatía. Este paisaje de violencia, desvinculado y cosificado, naturaliza la muerte y legitima el asesinato de los otros, de esos otros que, por su

1. Durante el trabajo de campo adquirimos conciencia de que el término favela es despreciativo y puede ser utilizado para humillar y marcar distancias de clase y raza. En este sentido, usamos los términos favela y favelado con mucho cuidado y tenemos en cuenta que los habitantes de estos territorios han resignificado dichas palabras con el fin de rescatar la dignidad, la resistencia, la crítica y la lucha de quienes se identifican como periféricos. 
color de piel o su origen de clase, resultan enemigos de un proyecto de sociedad neoliberal moderna/colonial. Sin separar las preocupaciones por la violencia de género de las matrices de opresión racistas y coloniales, Segato (2018: 11) habla de una pedagogía de la crueldad que refiere a "todos los actos y prácticas que enseñan, habitúan y programan a los sujetos a transmutar lo vivo y su vitalidad en cosas".

En diálogo con Segato (2018), Nilma Lino Gomes y Ana Amélia de Paula Laborne (2018) resaltan el peso de la política de seguridad cruel y racista que cada año mata a la gente negra de manera sistemática y desproporcionada en Brasil, como ocurre en el caso de las favelas de Rio de Janeiro, donde las profesoras realizan su trabajo en comunidades acechadas por la violencia del Estado y por grupos armados delincuenciales. En 2017, el Atlas de la Violencia en Brasil relató que "de cada 100 personas que sufren homicidio en el país, 71 son negras. Jóvenes y negros de sexo masculino continúan siendo asesinados todos los años como si vivieran en una situación de guerra" (Cerqueira; Lima; Bueno, 2017: 30).

El homicidio de jóvenes negros por parte de la policía revela datos alarmantes. La Red de Observatorios de Seguridad Pública (Rede de Observatórios da Segurança, 2020) registró, en 2019, la cifra más alta de violencia letal policial en los últimos treinta años en el estado de Rio de Janeiro, con 1814 personas asesinadas. De estas, $86 \%$ eran personas negras, un dato apabullante si se tiene en cuenta que en ese estado apenas el $51 \%$ de la población se autoreconoce bajo dicha categoría étnica. El informe citado es contundente al señalar que "en Rio, el racismo de la seguridad pública y de la cultura policiva es explícito y se ejerce sin disfraces. Es en las favelas que la policía realiza operaciones cotidianas y mata sin control" (Rede de Observatórios da Segurança, 2020: 21). Los cuerpos de las personas negras, en especial de los jóvenes, cargan con las marcas del color del miedo (Gomes; Laborne, 2018).

El público escolar de las favelas, compuesto mayoritariamente por personas negras (pretos y pardos) ${ }^{2}$, está acorralado por un sistema de opresión con raíces esclavistas y coloniales, que los priva de sus derechos básicos y los somete a una lógica de criminalización que ha significado su exterminio físico y simbólico (Gomes; Laborne, 2018; Sorj, 2016; Veillette; Nunes, 2017). Este proceso de criminalización ha generado muerte, exclusión $\mathrm{y}$, a su vez, profundas heridas emocionales que se manifiestan en sentimientos de inferioridad, miedo y deshumanización.

La institución escolar en las favelas no ha sido neutral ante la reproducción del exterminio físico y simbólico de la juventud negra. Siguiendo el argumento del sociólogo Marcelo Burgos (2009), esta institución actúa en las favelas por medio de

2. A partir de 1991, los criterios censales correspondientes a la autodeclaración de raza/etnia del Instituto Brasileiro de Geografia e Estatística (IBGE) incluyen como opciones: branco, preto, pardo, amarelo e indígena. La categoría negro aglutina a las personas autodenominadas prietas y pardas. 
prejuicios, distanciamiento y pesimismo sobre los estudiantes y su futuro. Dicha actitud de docentes y directivas configura un efecto favela que establece una relación de antagonismo entre la escuela y el mundo de los estudiantes, un mundo marcado con el rótulo de la violencia, la precariedad y la deficiencia. Así, el discurso escolar no se aleja del policiaco, que ve a los niños y jóvenes favelados como bandidos, violentos e indisciplinados.

Sobre este panorama nos preguntamos: ¿qué hace la escuela para proteger la vida de los niños y los jóvenes negros?, ¿de qué manera los docentes pueden hacer una diferencia para que la escuela sea un espacio para la vida y no para el exterminio de la niñez y la juventud negra?, ¿cómo se puede cuidar la vida en un contexto escolar marcado por la violencia armada y el racismo?

Para intentar responder estos interrogantes, partimos de la premisa de que los docentes son figuras clave para liderar procesos orientados a la construcción de justicia social (Murillo; Hernández, 2014) ${ }^{3}$. En este sentido, nos interesa destacar la agencia de los docentes en el abordaje de las violencias armadas. Proponemos que el cuidado (como ética y praxis) constituye el núcleo de las acciones que realizan los docentes para mitigar los impactos de la violencia y proyectar posibilidades para la sanación parcial en contextos atravesados por la violencia armada.

Esto no quiere decir que el conflicto sociorracial que envuelve la violencia armada en Rio de Janeiro pueda ser resuelto solo por una educación comprometida con el cuidado. Sería injusto poner esta carga sobre la educación, las educadoras y los educadores y, sobre todo, estaríamos negando la responsabilidad que tienen el Estado y la sociedad en la perpetuación de las desigualdades que sitúan a las comunidades de las favelas en una posición subalternizada, racializada, empobrecida y excluida. Creemos que una praxis educativa basada en el cuidado no puede transformar por sí sola el conflicto, pero sí puede generar diferencias y articular puntos de vista críticos que habiliten posibilidades de vida en medio de las políticas del exterminio.

3. En el campo de la pedagogía, hay un amplio debate sobre las relaciones entre justicia social y educación, el cual no entraremos a describir por cuestión de espacio; sin embargo, vale la pena señalar que diferentes enfoques sitúan a las y los profesores como agentes de liderazgo en procesos de defensa de derechos humanos y lucha contra las desigualdades. Este tipo de liderazgo involucra acciones profesorales cotidianas que contribuyen a la construcción de escuelas más justas, por ejemplo, el interés y el trabajo por el bien común, el esfuerzo para que todos los alumnos aprendan, el fomento por el respeto y la dignidad de los individuos, la creación de espacios democráticos y participativos, la generación de conocimientos al servicio de la comunidad, entre otros. 
Para desarrollar este argumento, nos apoyamos en el diálogo que tejimos con profesoras de educación fundamental ${ }^{4}$ en escuelas de la zona norte de Rio de Janeiro. Analizamos cómo en su trabajo cotidiano se anuda una ética del cuidado para sobrellevar los impactos de la violencia armada sobre la comunidad escolar. A este trabajo lo hemos llamado pedagogía visceral. Con esta noción, buscamos englobar aquellas prácticas de cuidado que despliegan las profesoras con el fin de generar un entendimiento crítico de las opresiones que viven sus estudiantes, acoger los dolores y abrir entornos educativos para intentar combatir los devastadores efectos emocionales del racismo.

La pedagogía visceral habla de la importancia de abrirse a la historia y los sufrimientos de los cuerpos desde una perspectiva del cuidado y de la justicia social. Significa reconocer en las emociones una poderosa herramienta para desnaturalizar la violencia y luchar contra la estigmatización. Las profesoras con las que conversamos acogen la vulnerabilidad de sus estudiantes con el fin de acompañarlos en sus duelos, imaginar otros futuros y sembrar vida en circunstancias de dominación y exterminio. La pedagogía visceral no suele ser una salida mágica, pero engendra esperanzas de posibilidad y afectos vitales. Es una pedagogía que, de algún modo, desafía a la muerte. Inspiradas en la propuesta de Jorge Larrosa (2019:476), podemos pensar una pedagogía visceral como aquella que

lucha por una escuela como espacio lleno de posibilidades, de voces, de formas de narrar-nos, de nombrar el sufrimiento, el dolor y la muerte, más allá de ellas mismas y amarradas a los nombres que damos a la vida, a la sorpresa, a la posibilidad. Un espacio más acogedor dentro de lo inhóspito. Tal vez, apenas, un punto de partida posible para algo más.

\section{Ruta metodológica}

En este artículo, presentamos un análisis del trabajo de campo realizado en Rio de Janeiro por una de las autoras durante 2019 e inicios de 2020. Este ejercicio se inscribe en el marco de una investigación más amplia que busca analizar la ética y el trabajo de cuidado que realizan profesoras de educación básica en zonas de conflicto armado en Colombia y Brasils.

4. La estructura del sistema escolar brasileiro comprende la educación infantil, educación fundamental I (1. ${ }^{\mathrm{a}}$ a $5 .^{\mathrm{a}}$ serie para alumnos entre los 6 y 11 años), educación fundamental II ( $6 .^{\mathrm{a}}$ a $9{ }^{\mathrm{a}}$ serie, $11-15$ años) y Ensino Médio o secundaria, con una duración de tres cursos, y estudiantes con edades entre 15 y 18 años.

5. Actualmente, la tesis de doctorado desarrollada por Alanis Bello, con orientación de Cláudia Pereira Vianna, está en proceso de elaboración y hace parte del Área de Concentración Educação e Ciências 
En esta fase de la investigación, se realizaron nueve entrevistas semiestructuradas a profesoras de escuelas públicas ubicadas en favelas de las zonas norte y central de Rio de Janeiro ${ }^{6}$. Acompañamos las entrevistas con visitas in situ a dos escuelas, y un registro etnográfico de la cotidianidad escolar. Adicionalmente, hicimos un taller sobre pedagogías para la paz con profesores de la favela de Maré, en el que activamos procesos de conocimiento situado sobre las emociones docentes en situaciones de violencia. Por último, complementamos nuestro trabajo con observaciones en dos foros sobre el nexo entre escuela y favela, coordinados por el Departamento de Educación de la Universidad Estadual do Rio de Janeiro.

Gracias a los contactos establecidos en talleres y encuentros académicos, logramos acceder a un grupo de profesoras con un perfil vinculado a la investigación social y la participación en colectivos culturales, políticos y pedagógicos que operan en las favelas. En la búsqueda por identificar rasgos del cuidado en profesoras de la periferia carioca, privilegiamos a aquellas que tuvieran una amplia trayectoria laboral que diera cuenta de sentidos de responsabilidad con la comunidad escolar y permanencia en el territorio. Finalmente, seleccionamos a aquellas profesoras que tuvieran un papel de liderazgo en las escuelas, principalmente, en el desarrollo de estrategias pedagógicas para la protección y la garantía de derechos para niños, niñas y adolescentes en el marco de la violencia armada.

Las entrevistas se hicieron originalmente en portugués y luego fueron transcritas y sistematizadas. Para este artículo, tradujimos al castellano fragmentos de las narrativas de las docentes y buscamos ser lo más fieles posibles al tono y a las expresiones culturales que emplean las profesoras para narrar sus experiencias localizadas.

Por otra parte, siguiendo los protocolos establecidos por el Comité de Ética de la Facultad de Educación de la Universidad de São Paulo, elaboramos consentimientos informados con las profesoras, con el propósito de obtener autorización para el análisis de sus relatos, garantizar el anonimato de sus identidades y proteger sus datos. De este modo, los nombres de las escuelas y de las profesoras fueron cambiados u omitidos deliberadamente, buscando garantizar la seguridad de nuestras interlocutoras.

Sociais: Desigualdades e Diferenças, del Programa de Posgrado en Educación de la Facultad de Educación de la Universidad de São Paulo (Brasil).

6. La zona norte de Río de Janeiro se caracteriza por una alta presencia de favelas o territorios con un bajo índice de desarrollo humano (IDH) y una exclusión en el acceso a servicios públicos, a la vivienda digna y a una educación de calidad. Además, son territorios leídos por la sociedad brasilera como lugares violentos y, en consecuencia, han sido sometidos a las políticas de control militar. Algunos de los complejos de favelas más grandes de esta zona son Maré, Pavuna, Penha y Alemão, que han sufrido con mayor intensidad los procesos de intervención de la policía militar desde los años noventa. En la zona central, conocimos a una profesora que trabaja en una favela del barrio Santa Teresa que comparte aspectos comunes con las de la zona norte. 
Entrevistas, observaciones y talleres componen la metodología de estudio de caso que empleamos para mapear el vínculo entre trabajo docente, cuidado y violencia armada. Los estudios de caso, como señala Rebughini (1998), ponen bajo análisis diferentes procesos sociales desde una perspectiva de contexto, con el fin de conocer sus manifestaciones locales, variaciones y singularidades. En este sentido, la producción de conocimiento sobre un caso proviene de la posición del sujeto investigador en su relación con el contexto analizado.

Nuestra posición como investigadoras feministas nos condujo a pensar-con nuestras interlocutoras y a crear prácticas afectivas de conocimiento que nos acercaran a la vida cotidiana del ser docente en un contexto de violencia sin generar una acción con daño (Puig de la Bellacasa, 2012). Asimismo, nuestra relación con varias profesoras no se limitó al espacio de las entrevistas, sino que hemos mantenido un contacto permanente y un diálogo sostenido ante nuestro interés común por impulsar prácticas educativas emancipadoras que desafíen a las estructuras de violencia.

En este artículo, destacamos el trabajo que hacen profesoras autodenominadas negras y pardas, docentes con amplias trayectorias laborales en escuelas públicas de la región. Es importante mencionar que las profesoras viven en estas favelas y pertenecen a la clase social designada baja-media, lo que las aproxima a la experiencia de clase vivida por sus alumnos. En este sentido, consideramos importante destacar estas marcas de diferencia que encarnan las profesoras con el fin de evitar su asociación con el estereotipo de la maestra blanca cuidadosa (Henry, 2011). Para la pedagoga Annette Henry (2011), tal estereotipo reproduce la idea de que el cuidado es un asunto caritativo, y que las docentes -blancas- son heroínas que buscan salvar a niños de grupos subalternos con fines civilizatorios. Lejos de esta imagen, "la presencia histórica del cuidado entre profesoras negras ha estado asociado con la creación de estrategias educativas para la supervivencia comunitaria y su empoderamiento" (Henry, 2011: 269).

La ruta de este artículo es la siguiente: en la primera parte, abordaremos el marco conceptual que orientó esta reflexión, mediante un breve insight de la perspectiva del cuidado y el trabajo emocional como elementos centrales en el proceso del trabajo docente. En un segundo momento, describiremos las condiciones de trabajo que tienen las profesoras en las escuelas afectadas por la violencia armada. Finalmente, detallaremos las prácticas de cuidado en el contexto escolar que desafían a la muerte y su relación con la noción de pedagogía visceral. 


\section{Cuidado y trabajo emocional en la profesión docente}

El cuidado es una categoría de los estudios feministas utilizada como herramienta crítica para cuestionar los paradigmas dominantes sobre el empleo y el trabajo. El cuidado cuestiona la división sexual del trabajo y su efecto de subordinación sobre las actividades que contribuyen a la producción de la vida. El cuidado

no es apenas una actitud de atención, es un trabajo que abarca un conjunto de actividades materiales y de relaciones que consisten en ofrecer una respuesta concreta a las necesidades de otros. Así, podemos definirlo como una relación de servicio, apoyo y asistencia, remunerada o no, que implica un sentido de responsabilidad sobre la vida y el bienestar de otros. (Kergoat, 2016: 17)

Para las teóricas feministas, la perspectiva del cuidado cuestiona las relaciones de género que naturalizan las tareas de reproducción como asociadas de manera inherente a disposiciones femeninas (Hirata; Guimarães; Sugita, 2012). El cuidado es una actividad humana que podemos realizar todos y todas. Además, es una actividad necesaria para el sostenimiento de la vida que, por efectos de la dominación, suele ser invisibilizada y asociada con frecuencia a ciertos oficios feminizados (Arango, 2018). El debate feminista ha puesto el acento en evidenciar que el cuidado no se reduce a un oficio y que posee dimensiones éticas y políticas vinculadas a "mantener, continuar y reparar nuestro mundo, de manera que podamos vivir en él tan bien como sea posible" (Fischer; Tronto, 1990: 40).

Es importante mencionar que el cuidado es una actividad relacional que no puede ser reducida al amor y al altruismo, pues implica relaciones de poder, conflicto y ambivalencia que remiten a asuntos de justicia y desigualdad social (Arango, 2018). La perspectiva del cuidado permite analizar las desigualdades entre personas, grupos y sociedades, y pone de relieve la mala distribución del cuidado, no solo con relación al trabajo, sino también con el derecho a ser receptor de cuidados. El acceso desigual al cuidado marca posiciones de privilegio y opresión que expresan valoraciones desiguales de los cuerpos con base en jerarquías interseccionales de género, raza, clase y nacionalidad, entre otras (Collins, 2019).

En la literatura sociológica, la docencia ha sido identificada como un trabajo de cuidados, no solo porque la mayor parte del cuerpo magisterial (especialmente en la educación básica) está compuesto por mujeres, sino porque la enseñanza envuelve dimensiones cognitivas, relacionales y emocionales necesarias para su buen funcionamiento (Carvalho, 1999; hooks, 2010; Zembylas, 2007).

Los procesos educativos están estructurados por tramas emocionales que involucran el afecto y las agencias de docentes y estudiantes. Para Isenbarger y Zembylas 
(2006), las dimensiones del cuidado en la enseñanza implican una movilización de afectos y disposiciones por parte de los docentes para atender las necesidades educativas de sus estudiantes. Comprende la capacidad de escuchar, de mostrar sensibilidad frente a sus problemáticas, en síntesis, el trabajo docente es indisociable del trabajo emocional. Nuestra aproximación a las emociones retoma la noción de trabajo emocional de la socióloga Arlie Hochschild (1979), para dar cuenta de las relaciones de cuidado que establecen docentes, estudiantes y familias, en el contexto escolar. La perspectiva del trabajo emocional destaca la acción reflexiva de los docentes frente a sus propias emociones y las de otros. Es decir, hay un reconocimiento de su esfuerzo cognitivo, corporal y expresivo para negociar las reglas del sentir que rigen un determinado territorio.

El trabajo emocional de los docentes se realiza bajo ciertas condiciones sociales modeladas por poderes económicos, políticos y sociales. En las últimas décadas, las emociones docentes se han tornado objetos pasibles de control, instrumentalización $\mathrm{y}$ vigilancia. Tal giro en la gestión educativa ha significado la imposición de una agenda gubernamental que fomenta lógicas empresariales dentro de los currículos y las escuelas. Este fenómeno que ha sido denominado en la academia brasilera como emocionalización pedagógica (Silva, 2017), se basa en la diseminación de prácticas administrativas y psicológicas en los contextos escolares, con el fin de formar sujetos capaces de regular sus emociones y adquirir competencias que les permitan ser flexibles y adaptarse a los mandatos del mercado de trabajo.

El discurso de las competencias socioemocionales dentro del ámbito escolar, afirman Ciervo y Silva (2019), ha sido aceptado para la reproducción de un ethos neoliberal que promueve la competencia y el individualismo como derroteros de toda práctica educativa. Los defensores de las competencias socioemocionales asumen que el ideal de alumno es el de un sujeto resiliente, capaz de poner sus emociones y fuerzas al servicio del éxito individual y laboral. Resiliente es aquel capaz de adaptarse a las reglas impuestas por el mercado, aquel que no cuestiona el orden de las cosas y que se muestra dispuesto a perseverar, a pesar de no contar con condiciones sociales privilegiadas.

Como señalan Carvalho, Oliveira, Modesto y Silva Neto (2020), las políticas gerencialistas en el campo escolar han contribuido a desvirtuar los fines de la educación, toda vez que enfatizan lógicas de medición, competencia, individualismo y burocratización, en desmedro del conocimiento. Así, las reglas del sentir que gobiernan el trabajo escolar demandan que las y los docentes autorregulen sus emociones, con el propósito de mostrar resultados eficientes en la enseñanza; asimismo, se espera que el control emocional les permita soportar condiciones precarias de trabajo, tolerar la explotación laboral y sentir culpa en caso de que sus estudiantes 
fracasen en los estudios. El trabajo emocional articula formas de control sobre el trabajo docente, pero, a su vez, articula posibilidades de cuidado y de resistencia ante las lógicas del mercado. No menos importante es señalar que el trabajo emocional tiene potencialidades para reparar y subvertir los contextos de guerra que proliferan en las sociedades contemporáneas.

En esta línea de reflexión sobre las reglas del sentir que configuran las relaciones pedagógicas, Quintero, Sánchez y Ballesteros (2019) han puesto en evidencia que en situaciones de conflicto armado las y los docentes desarrollan sus emociones en estrecho vínculo con las relaciones de poder que se viven en un territorio determinado. Nos parece sugerente su noción de geopolítica de las emociones, ya que permite observar que los acontecimientos violentos no solo se experimentan como hechos históricos, sino como huellas emocionales susceptibles de ser identificadas en las narrativas docentes. Retomamos de este planteamiento la importancia de reconocer en las narrativas docentes una doble potencialidad política: por un lado, reflejar la memoria de los daños y la dimensión de las violencias que afectan a las comunidades; y, por otro, encontrar en sus resistencias posibles alternativas para configurar emociones públicas proclives a la paz, la sanación y la justicia.

La geopolítica emocional que rige las escuelas de la periferia carioca se constituye por fuertes discursos de odio que apalancan jerarquías raciales, estigmatización y miedo. El miedo parece permear la cultura escolar. En nuestro trabajo de campo, encontramos que hablar de la violencia armada, del racismo y del derecho a la vida de la juventud negra era algo poco frecuente o deliberadamente evitado. Hay una norma de silencio que naturaliza el trauma sufrido y la acumulación de violencias. A menudo, las maestras han aprendido a poner límites en sus acciones para evitar ser vistas con sospecha por la policía militar o, incluso, evitan hacer denuncias de las injusticias por miedo a las represalias. Las profesoras en las favelas lidian en la vida cotidiana con el temor, el silencio y la muerte.

En este punto, cabe mencionar que las emociones no solo se experimentan de manera represiva, sino que también constituyen poderosas herramientas para la transformación social. En la sociología hay una rica documentación sobre cómo los docentes, en diferentes contextos, han encontrado caminos para subvertir las reglas emocionales dominantes, resistir y crear conexiones afectivas para conseguir la paz, la reparación y el perdón (Quintero et al., 2019; Zembylas, 2007). Cuando la docencia se vuelca sobre un trabajo emocional comprometido con la producción de afectos y la defensa de la vida, puede ser capaz de provocar subversiones a las políticas de muerte que imponen los contextos de violencia armada.

El cuidado y sus agencias emocionales constituyen, para el pensamiento feminista, una práctica disruptiva; es un modo de pensamiento y de acción comprometido 
con el mantenimiento y el sostenimiento de la vida bajo coordenadas no inocentes, parciales y transformadoras (Haraway, 2019). Esta forma de ver y actuar involucra un posicionamiento político que aboga por el reconocimiento de la vulnerabilidad compartida y por la proliferación de otras relaciones y formas de conocer, no regidas por la distancia objetiva o la jerarquía. Cuidar es pensar-con y dejarse afectar (Puig de la Bellacasa, 2012); el cuidado involucra responsabilidad y quienes cuidan se sienten movidos por el otro. Moverse, implicarse y sentir con otros implica apuestas de generación de mundos alternativos. En ese sentido, el cuidado es una consciencia opositiva y una forma de vinculación para crear mundos, quizás, más justos (Puig de la Bellacasa, 2012: 208).

Partimos de la comprensión del cuidado como un terreno ambivalente que involucra trabajo, afectos y posturas políticas. El cuidado engendra satisfacciones, pero también puede ser agobiante. Las profesoras en la periferia carioca ejercen prácticas de cuidado en condiciones materiales convulsionadas por relaciones de violencia, racismo y exclusión estatal. Simultáneamente, su ejercicio docente ocurre en condiciones de precarización laboral, baja remuneración y una gran explotación emocional.

A continuación, abordaremos cómo la violencia armada y la marginalización exponen a las profesoras y a los estudiantes a un riesgo de muerte. Exploramos cómo esas violencias configuran condiciones laborales precarias que aumentan las cargas del trabajo de cuidado que realizan las profesoras en las escuelas de las favelas.

\section{Profesoras entre el fuego cruzado: condiciones laborales}

Las profesoras con las que conversamos han trabajado entre 8 y 22 años como docentes en la red pública de enseñanza de Rio de Janeiro; todas entraron en la carrera docente por medio de concursos y tienen, en promedio, contratos de 40 horas semanales. Algunas de ellas dividen su tiempo de trabajo, o matrículas como lo llaman, entre escuelas administradas por la alcaldía municipal y por el gobierno del Estado. Al momento de la entrevista, tenían una media salarial de 476 dólares mensuales 7 , un hecho que consideran desestimulante y por el cual se ven obligadas a trabajar en varias escuelas para complementar su salario. Así fue indicado por Camila, de 39 años, que se desempeña como profesora de Historia en una escuela de la favela de Penha.

Camila: Yo trabajo en tres escuelas, mi escuela nocturna es del estado [de Rio de Janeiro]. Es mucho trabajo. 
Investigadora: ¿Por qué tienes tres trabajos?

Camila: Porque los salarios son muy malos, es necesario por una cuestión económica, financiera. Es para tener más dignidad (...), por eso es necesario realizar todo ese trabajo (Camila, comunicación personal, 03.10.2019).

Las largas jornadas que enfrentan la mayoría de profesoras hacen que no tengan tiempo para preparar sus clases, continuar procesos de formación o participar en equipos de docencia. Tal situación aumenta la dependencia de los materiales producidos por las autoridades educativas, lo que afecta su autonomía y capacidad para profundizar en otras prácticas de conocimiento: "No tengo tiempo para preparar clase. Yo no planifico, solo consigo orientarlos" (Camila, comunicación personal, 03.10.2019).

Como ya fue mencionado, las docentes entrevistadas provienen de comunidades faveladas y se autoidentifican como mujeres negras y pardas. Para algunas de ellas, la carrera docente apareció como una posibilidad de ascenso social dentro de un mercado laboral restringido por jerarquías de raza, género y clase. Por ejemplo, antes de volverse profesora, Rosana trabajó como estilista y en otras actividades que incluían el cuidado de bebés y venta de productos por catálogo. Dejó su anterior trabajo y optó por formarse como docente de educación infantil, "porque era un curso relativamente corto y accesible" (Rosana, comunicación personal, 02.10.2019). Con el paso del tiempo hizo un pregrado en Pedagogía en una universidad pública y, desde el año 20oo, trabaja en la Secretaría Municipal de Educación en cargos de docencia y asistencia técnica.

Rosana se mostró muy comprometida con su trabajo docente con niños perjudicados por la violencia armada, y relató que dicho compromiso estaba conectado con su propia vivencia como mujer racializada y de clase popular. Hay una identificación de historias, una experiencia de marginalidad que ella transformó en compromiso.

Esa situación de ser territorio violento aumentó, potencializó mi voluntad de ser profesora. Porque ellos necesitan mucho más que aquel alumno que está en una escuela particular, que tiene dinero, que va para Disney y que no está en medio del tiroteo. Y pues, yo también vengo de clase popular, mis papás solo estudiaron hasta cuarto de primaria, son nordestinos. Allá en casa somos 3 hermanos, todos de escuela pública, conocemos esa dificultad. Eso solo refuerza mi deseo de ser profesora, de tener resistencia, de mostrarles que somos capaces y que con educación llegamos a algún lugar. (Rosana, comunicación personal, 02.10.2O19)

Como mujeres negras, las profesoras entrevistadas relataron que sus trayectorias laborales y educativas fueron marcadas por la exclusión, el racismo y el sexismo (Collins, 2019). Muchas encontraron en el magisterio una oportunidad para escapar, de 
algún modo, de la reproducción de ciclos de marginación que "concentran a la mayoría de las mujeres negras dentro del mercado informal de trabajo" (Biroli; Miguel, 2015: 43). La profesión docente representa una ruptura con las posiciones de "la mulata, la doméstica y la mãe preta" que apresan a las mujeres negras brasileras (Gonzalez, 1983:224), y abre posibilidades para una afirmación como agentes productoras de conocimiento al servicio de sus comunidades. Para nuestras interlocutoras, la profesión docente va más allá de un trabajo, y comporta significados colectivos y compromisos con las reivindicaciones políticas de las comunidades negras y faveladas.

La carrera docente de las profesoras ha transcurrido por escenarios escolares afectados por la violencia armada que aqueja a las favelas. En el contexto de Rio de Janeiro, encontramos que las favelas ocupan el lugar de las márgenes, respecto a la ciudad o al asfalto, como se les conoce a los barrios de las clases media y alta. Oliveira (2014) sostiene que, desde su emergencia a finales del siglo XIX, las favelas han sido representadas como territorios ajenos a la soberanía estatal. Esto ha implicado que sean vistas no solo como lugares habitacionales con condiciones precarias, sino que son un foco de valoraciones negativas que las han producido como lugares incivilizados, peligrosos y amenazantes para los habitantes del asfalto.

En las últimas décadas, colectivos criminales como el Comando Vermelho o el Terceiro Comando da Capital, así como grupos de paramilitares conocidos como milicias, se han instalado en las favelas ejerciendo cierto control sobre la vida de los habitantes y disputando un mercado creciente de tráfico de drogas y de seguridad privada. En los medios de comunicación y los sistemas de información del Estado, las favelas han sido construidas como territorios del crimen, lo que devino en la producción de una metáfora de guerra que justificó su militarización y una fuerte criminalización de las comunidades faveladas (Oliveira, 2014:35).

Un hito de estas políticas fue la creación de las Unidades de Policía Pacificadora (UPP), en 2008, por el Gobierno del Estado de Rio de Janeiro, cuya acción en los territorios ha consistido en reprimir a los habitantes de las periferias y desatar operativos militares con el pretexto de retomar la soberanía. La política de pacificación es heredera del orden colonial brasilero y, en la actualidad, constituye un dispositivo que refrenda formas de racismo y exclusión sobre los habitantes de las periferias (Oliveira, 2014).

Según Farias (2007), la represión policial sobre los favelados opera como una de las principales tecnologías gubernamentales del Estado sobre dichos territorios, lo que ha generado el efecto de construir a estos sujetos como cuerpos matables. Figuras

8. Mãe preta se puede traducir como "madre negra", una figura de la ideología esclavista brasilera que impuso a las mujeres negras el estereotipo de ser las encargadas de criar y dar amor a los hijos de los patrones blancos. 
como las del bandido, el traficante y el individuo peligroso son utilizadas como estigmas por la fuerza policial para controlar y asesinar. Estas marcas poco distinguen a los habitantes de las periferias de los miembros de los colectivos criminales, provocando actos atroces como los homicidios perpetrados por la policía bajo el amparo de la figura legal del auto de resistencia (Veillete; Nunes, 2017). La llamada política de pacificación, como señalan Machado da Silva y Leite (2015:147), resultó en "altas tasas de homicidios practicados por policías en las favelas, sin impacto considerable sobre el dominio militar de los traficantes de drogas y en el establecimiento de relaciones con los habitantes, marcadas por tensión, desconfianza y violencia”.

Una de las mayores preocupaciones de las profesoras es el incremento del intercambio de tiros y las operaciones policiales alrededor de las escuelas. Bruna, de 35 años, es profesora de educación fundamental II en una escuela pública localizada en el Complexo da Penha. Ella narró que, en 2018, su escuela, así como otras de la región, fue obligada a interrumpir las actividades escolares porque la policía ingresó de manera arbitraria en las instalaciones educativas.

En 2018 tuvimos la interrupción de una semana continua de clases, en el Complexo da Penha. Exactamente porque tuvimos dos escuelas que fueron tomadas por las fuerzas policiales, ellos entraron, acamparon, y la dirección de la escuela dijo: “¿Cómo es que voy a abrir la escuela con un policía dentro de la escuela?", de veras que acamparon y se quedaron una semana dentro del patio de la escuela. En dos escuelas sucedió eso. (Bruna, comunicación personal, 30.09.2019)

El cotidiano escolar aparece marcado por un fuego cruzado en el que los efectos más visibles son el cierre frecuente de las escuelas y la violación al derecho a la vida y la seguridad, tanto de estudiantes como de docentes. Pero sus efectos más potentes tienen que ver con la instauración de una geopolitica emocional del miedo en la escuela, donde las profesoras y los estudiantes viven de manera cotidiana bajo una sensación constante de real o potencial amenaza (Quintero et al., 2019). Las profesoras manifestaron sentir miedo de que una bala pudiera acabar con su propia vida y la de sus estudiantes, como sucedió con el asesinato de Maria Eduarda da Conceição, una niña de 13 años que fue asesinada en 2017 dentro de una escuela en la favela de Acari, por un tiro de fusil que un policía militar disparó en un combate con una facción criminal (GloboNews; RJTV, 2017).

En 2018, fueron registrados 305 tiroteos en la ciudad de Rio de Janeiro, los cuales impactaron directamente a 170 instituciones de educación pública, especialmente en horario escolar (entre las 7:00 a. m. y las 5:00 p. m.). En ese mismo año, se registraron los asesinatos de tres alumnos dentro de las escuelas y de un docente (2018: 342 tiroteios/disparos, 2019). 
Las profesoras identifican que las operaciones militares alrededor de las escuelas no suelen ser previamente informadas, a pesar de que la policía tiene el deber legal de comunicar dichas acciones. Esta relación turbia que establece la fuerza pública con la escuela produce pánico entre las familias, que deben ver cómo sus hijos e hijas quedan atrapados en las instituciones educativas en medio de los enfrentamientos. Esta situación expone a la comunidad escolar a la muerte y al daño y, sin duda, produce una grave afectación al derecho a la educación de calidad que se ve socavado por "una combinación perversa de exclusión social y violencia armada" (Plataforma DhESCA, 2008: 8).

Sobre este punto, conversamos con Rosana, quien fue profesora de educación fundamental I durante varios años, en una escuela ubicada en el Complexo de Chapadão. En su narración, se observa que el trabajo escolar se ve afectado por la violencia que enfrentan los estudiantes y sus familias. En muchas ocasiones, se trata de una experiencia chocante que produce perplejidad e impotencia:

los niños ven la escuela como un local de cuidado, como un local de seguridad porque muchos no la tienen en su propia casa, porque la policía invade, porque la casa es muy frágil. (...) Yo creo que el cuidado va más allá de lo físico, es lo emocional que buscamos atender porque muchos de ellos no duermen y llegan a la escuela cansados porque hubo tiroteo, porque al lado de sus casas hay microondas (...). Son llantas que ellos colocan una sobre otra, y alli dentro colocan personas para poder ejecutarlas (...). Ya un niño relató que eso era al lado de su casa, relató los gritos de pavor, de horror. Son situaciones que una ni imagina, ni en una película, que puedan pasar. (Rosana, comunicación personal, 02.10.2019)

A partir de las miradas de las profesoras. se fue formando una representación de la niñez y la juventud como grupos sociales desprovistos de cuidados, producidos por las políticas de seguridad, segregación económica y racismo que imperan en el territorio. Las profesoras hablaron de estudiantes rotos por el duelo de familiares asesinados o encarcelados, de jóvenes cooptados por los colectivos criminales y de casos aberrantes de violencia sexual. También mencionaron difíciles experiencias de precariedad material, hambre y depresión, así como situaciones en las que los niños tuvieron que testimoniar asesinatos y masacres.

Una de las principales problemáticas relacionadas con la violencia armada que afecta a las profesoras consiste en que no consiguen dar continuidad a su trabajo pedagógico. Las violencias sobre las comunidades hacen que los alumnos experimenten una alta rotatividad y evasión escolar. Esto significa que las docentes, por un lado, tienen problemas para cumplir satisfactoriamente con las metas formativas oficiales y, por otro, que no consiguen acompañar adecuadamente los avances en los 
aprendizajes de los estudiantes. Que los estudiantes no consigan aprender resulta frustrante y desesperanzador para las docentes.

Según las profesoras, la violencia armada produce un grave daño en la salud mental y física de sus estudiantes. A veces, las profesoras tienen que lidiar a diario con las marcas del trauma sin respaldo de la escuela o de profesionales idóneos que puedan encargarse de ofrecer atención psicosocial. Los efectos de la violencia son tan intensos que terminan envolviendo las relaciones pedagógicas y emergen demandas de cuidado ineludibles que, en ocasiones, no logran ser maniobradas por las docentes. Es frecuente que ellas se sientan impotentes y atribuladas. Muchas ignoran cómo responder a las exigencias de atención emocional que precisan sus estudiantes. Bruna informó que:

los estudiantes llegan con tristeza, apatía, indiferencia. Muchas veces con un comportamiento muy diferente de lo que es su comportamiento regular, sobre todo los que pasan por los traumas. (...) Es difícil lidiar con las emociones porque no estoy preparada académicamente para eso, y a veces no sé cómo actuar, pero intento hablar con ellos. (Bruna, comunicación personal, 30.10.2019)

En la mayoría de las escuelas no se suele comprender el cambio de comportamiento y el daño emocional que viven los estudiantes favelados. El efecto favela, que impone una relación de antagonismo entre la cultura escolar y el mundo de los estudiantes (Burgos, 2009), posee una dimensión racial que reproduce una política emocional negativa sobre los jóvenes y niños negros. La profesora Sabrina, quien trabaja en una escuela cercana al Complexo do Alemão, uno de los barrios más azotados por la política de pacificación en Rio de Janeiro, mencionó que la escuela no es empática con el trauma que vive la niñez negra. Para ella, asumir una actitud cuidadosa significa no ignorar o reducir los impactos del racismo en la escuela y, por consiguiente, priorizar el entendimiento emocional de la situación de sus estudiantes antes que enfatizar las sanciones o la disciplina.

Yo creo que el racismo en la escuela está presente (...). Creo que el alumno negro es el inquieto, él es considerado un desajustado, él es considerado incapaz, con dificultades. Es solo que usted coja el registro de disciplina escolar y verá que los profesores escriben, hacen relatos de los alumnos, generalmente los relatos son negativos. Usted no ve ningún elogio, nada de buena conducta, no hay nada de eso escrito. (Sabrina, comunicación personal, 09.12.2019)

El racismo que inocula la disciplina escolar también está presente en las prácticas pedagógicas, el currículo y la evaluación. Frente a este último punto, la profesora 
Camila se mostró irritada. Para ella, las políticas de evaluación privilegian la gestión educativa de acuerdo con principios de control, eficiencia y promoción automática, que "minimizan el contenido para poder mostrar resultados" (Camila, comunicación personal, 03.10.2019). Esta transformación en la gestión educativa, en alza desde los años noventa, ha implicado una precarización del trabajo docente y un rumbo diferente para la función de la educación, que ahora pasaría a "dispensar contenidos escolares también porque se volvió objeto de asistencia social y de la seguridad pública" (Catini, 2019:37).

Camila se mostró comprometida en hacer que su docencia sea un trabajo riguroso desde el punto de vista académico, por eso es exigente con sus estudiantes y les pide que se esfuercen en el aprendizaje de los contenidos. Ella considera injusto el hecho de que la escuela solo ofrezca a los estudiantes favelados un currículo mínimo. Su postura de cuidado la llevó al conflicto con las políticas educativas que reproducen una enseñanza mínima y una ciudadanía limitada.

En mi militancia hago una selección de contenidos que obviamente son preseleccionados por la institución, por el gobierno (...). Solo que, en ese diagnóstico del discurso oficial, siempre existe una inferiorización de la clase pobre y periférica, como si ellos no consiguieran nunca estudiar por las cuestiones del conflicto, por las cuestiones familiares que ellos viven. Entonces, el currículo es mínimo. Eso significa que ellos tienen que aprender lo mínimo (...). En ese mínimo, ellos quedan sin condiciones de competitividad, de movilidad y quedan sin condiciones de ejercer la ciudadanía de forma efectiva, la ciudadanía queda limitada. (Camila, comunicación personal, 03.10.2019)

Como se observa, la institución escolar en las periferias de la ciudad de Rio de Janeiro parece asumir un comportamiento diferencial con su público: le ofrece un mínimo de capital cultural y académico, restringiendo, de esa manera, su derecho universal a la educación de calidad. En términos de Rancière (2004: 24), podemos decir que, para los segmentos empobrecidos y negros, se ofrece una educación embrutecedora que, en vez de emancipar, refuerza las imágenes de inferioridad e incivilidad con las que la sociedad del asfalto ha visto siempre a las favelas.

Las condiciones de trabajo de las profesoras en escuelas marcadas por la violencia armada se caracterizan por no garantizar seguridad para el ejercicio de la docencia. Las profesoras y los estudiantes se ven enfrentados a tiroteos, cierre de escuelas y operaciones militares que articulan políticas de exterminio y geopolíticas emocionales del miedo (Gomes; Laborne, 2018). Sumado a esto, las docentes reciben bajos salarios y trabajan en condiciones de explotación y déficit de tiempo. El trabajo docente es obstaculizado por la violencia que perjudica a los estudiantes y sus familias; una violencia cruel que produce traumas, daños físicos y mentales, así como la muerte. 
Es en este contexto donde las docentes despliegan un trabajo emocional y de cuidado para navegar en medio de la violencia. Este cuidado raramente suele ser valorizado.

La situación de violencia y de falta de políticas sociales se traduce en una sobrecarga de trabajo sobre los hombros de las profesoras, quienes intentan ofrecer, en la cotidianidad, una atención psicosocial y de cuidado que el Estado no ofrece; por el contrario, este parece manifestarse en las favelas solo por medio de operaciones militares que reproducen políticas racistas y clasistas de exterminio. Dicha realidad produce profundos daños emocionales en docentes y estudiantes. Las profesoras que trabajan en medio del fuego cruzado experimentan un gran agotamiento, abandono, una experiencia carnal de burnout.

\section{Una pedagogía visceral: cuidado y afirmación de la vida}

En esta última parte, daremos cuenta del cuidado y el trabajo emocional que realizan las profesoras y cuyo efecto mitiga, en algún grado, las políticas de muerte que victimizan a la niñez y la juventud faveladas. Este cuidado parte de la conciencia de que el abordaje pedagógico de las emociones es un componente fundamental para desnaturalizar la violencia armada, e implica darle importancia al abordaje de los dolores generados por las políticas de exterminio.

Siguiendo a la teórica feminista bell hooks (2003), el racismo, históricamente, ha promovido una actitud de desconsideración hacia el bienestar psicosocial de las personas negras. Como producto de la colonización y los legados de la esclavitud, las personas negras han sido deshumanizadas. Los esfuerzos por mejorar su autoestima, potenciar su espiritualidad y promover el amor propio han sido descalificados, mientras los imaginarios sociales y educativos que demonizan a la juventud negra están dirigidos a "silenciar cualquier intento de nombrar el dolor del racismo y demandar de los blancos su responsabilidad" (hooks, 2003: 60).

Romper con el silencio, abrazar el dolor del otro y generar conexiones afectivas se convierten en coordenadas de una posible pedagogía crítica del cuidado: una pedagogía antirracista. En palabras de Segato (2018), sería una contra-pedagogía de la crueldad. No obstante, consideramos que las profesoras de Brasil no se oponen tan claramente a un proyecto estatal y patriarcal de dominación por medio de resistencias, como sugiere la autora cuando trata de las contra-pedagogías de la crueldad. En nuestra experiencia, lo que vimos con esas profesoras fueron modos diversificados de construir una pedagogía para vivir o sobrevivir en un cotidiano violento con actitudes pequeñas, pero significativas, que enseñan posibilidades contradictorias de cuidar de sí y de sus alumnos y alumnas. 
El cuidado es un trabajo considerado fundamental para la realización de una buena práctica docente. Así lo sugiere hooks (2010) en otro trabajo titulado Teaching Critital Thinking, donde señala que la docencia que se interesa por el crecimiento emocional e intelectual de los estudiantes abre el camino para que surjan el aprendizaje, la autonomía y el pensamiento crítico. Tradicionalmente, se ha pensado que el lugar del docente debe ser el de la razón, la objetividad y la formación cognitiva. Dicha percepción se encuentra muy anclada a los imaginarios del conocimiento occidental, blanco y masculino que conciben al alumno como un sujeto pasivo y sin historia personal: un recipiente vacío que hay que llenar con saber. Esta forma de concebir la docencia refuerza la dominación y "promueve un objetivismo calculado que es deshumanizante" (hooks, 2010: 31).

Rosana expuso que su experiencia de trabajo como profesora está vinculada a una ética del cuidado más que a una posición objetivista. Ella empezó a desarrollar un estilo docente sensible a las emociones de sus estudiantes, tras experimentar de cerca varios tiroteos mientras estaba con ellos en el salón de clase. Esta situación de intentar proteger su propia vida y la de los niños la llevó a afianzar un estilo de docencia basado en el compromiso emocional:

Y fue ahí que comencé a pensar: “¿y ellos?, ¿cómo no voy a volver a la escuela?”. Ellos están esperando, y de ahí viene un compromiso mucho mayor que el miedo, no es que no tenga miedo, porque sí que tengo, pero es un compromiso emocional, yo creo que queda mejor delimitado de esa forma porque yo necesitaba volver. Volví y concluí un año en esa escuela. (Rosana, comunicación personal, O2.10.2019)

El trabajo que realizan las profesoras en el contexto de violencia armada que afecta a las periferias pasa por un registro carnal, afectivo y relacional. El contacto con niños y jóvenes en los salones de clase va más allá de la transmisión de contenidos. Las experiencias de privación y sufrimiento que llevan los estudiantes en sus cuerpos no son evitables y terminan impregnando la práctica educativa. Las profesoras con las que hablamos ejercen su trabajo en el contexto de una política que sofoca los cuerpos, donde los estudiantes encarnan, como diría Mbembe (2019), cuerpos que no respiran, expuestos a la muerte, al trauma y a la vulneración de derechos.

A través de su experiencia y vinculando trabajo intelectual y praxis, las maestras han tejido en su práctica cotidiana una pedagogía visceral basada en el cuidado, el contacto, la atención emocional y el ejercicio de prácticas de supervivencia para intentar proteger y potenciar la vida de sus estudiantes. Esta forma de actuar se materializa en la cotidianidad de la escuela y no constituye un corpus de conocimiento formal. La visceralidad nos habla de un proyecto de politización de los dolores, de 
la posibilidad de abrirse a la identificación de lo común en el salón de clase, por medio de una actitud reflexiva y atenta a la vulnerabilidad, a los daños clavados en el corazón y a la escucha afectiva (Mbembe, 2019). En esta sección, intentamos recuperar estas prácticas con el fin de evidenciar que las docentes contribuyen, con su trabajo, a desafiar las políticas de exterminio sembrando esperanza y amor, pero también sufriendo un alto costo asociado al agotamiento y la invisibilidad.

Un primer rasgo de esta pedagogía visceral es que las profesoras, así como otros miembros de la comunidad escolar, despliegan acciones para protegerse en medio de los tiroteos. Todas las profesoras mencionaron estrategias para localizar a los estudiantes en puntos seguros de la escuela, de manera que no los alcancen las balas. Con la reiteración de los enfrentamientos, las profesoras dejaron de asumir estados de shock y desesperación, y pasaron a ejercer un control emocional para intentar contener la situación y transmitir sensaciones de calma a los alumnos. Dicho trabajo emocional no garantiza que nada malo pueda ocurrir, y a las profesoras solo les resta "pedir a Dios para que proteja a todo el mundo" (Rosana, comunicado personal, 02.10.2019).

Un segundo rasgo tiene que ver con la proximidad física y emocional. Bruna manifestó que no le es posible dar clase de geografía sabiendo que el día anterior hubo tiroteos en el barrio, quema de autobuses y hasta homicidios. Ella desarrolla una especie de protocolo con sus estudiantes y otorga importancia al hecho de abrir tiempos para hablar sobre lo ocurrido. No omitir la realidad es clave para actuar en este contexto, así como darle palabras al sufrimiento. Ante la actitud distante y desconfiada de la institución escolar, Bruna plantea un estar cerca, y agrega que no le es posible ser cariñosa con todos sus alumnos -que son más de 300-, pero sí consigue estar atenta y transmitir sensaciones de disponibilidad emocional cuando ellos la requieran:

Estar atenta es cuando usted consigue captar las singularidades, identificar las dificultades, circular por la sala y evita quedar siempre solo al frente del grupo sin ningún contacto. Yo creo que hasta físicamente es importante que usted también circule y se muestre presente, entiendo estar atenta en ese sentido. (Bruna, comunicación personal, 30.09.2019)

En consonancia con esta idea de estar cerca, Camila nos habló de una práctica simple, pero muy significativa: el acto de tocar como expresión de cuidado y afecto. A veces las experiencias de trauma son inenarrables y las palabras no alcanzan para revelar los efectos de la violencia. Como argumenta bell hooks (2010: 156), "en la cultura dominante, donde los cuerpos son enfrentados uno a otro y hechos para permanecer en un lugar de diferencia que deshumaniza, el tocar puede ser un acto de resistencia”. Camila considera que tocar a sus estudiantes aumenta su autoesti- 
ma, sobre todo cuando se trata de jóvenes negros que enfrentan un mundo racista que considera que sus cuerpos son peligrosos y no merecedores de afecto. De algún modo, tocar ayuda a aprender y a sanar.

Camila: No me puedo quedar presa solo al contenido. Entonces yo pregunto: (...) ¿están cabizbajos, se sienten solitos? Yo voy y pregunto: ¿por qué están tan aislados? Hago un toque, por ejemplo, beso sus cabezas, hago un cariño en el cabello y pues ellos son carentes de eso.

Investigadora: ¿Usted cree que eso ayuda un poco?

Camila: ¡Claro que ayuda! Ayuda porque ellos no tienen eso y pues hago estas cosas de manera desinteresada. A veces la mamá está trabajando, quedan solitos todo el día, pasa el bus, llegan a la escuela y a veces llevan su regaño por causa de su desorden, entonces yo los regaño, a veces, pero también les doy cariño, eso, por medio de un toque. Toco la mano, toco el cabello, creo que tocar es muy relevante. El aprendizaje pasa por la afectividad, si te caigo bien me vas a escuchar, si no, no vas a escuchar lo que tengo para decir. (Camila, comunicación personal, 03.10.2019)

Un cuarto rasgo que identificamos pasa por la práctica de hacer de la educación una bandera de luch a contra la violencia y la exclusión. Bruna, quien trabaja con estudiantes entre los 14 y los 16 años, apuesta por mostrarle a sus estudiantes que la educación es un camino para traspasar barreras, para no envolverse con las bandas del narcotráfico, "o simplemente para mostrar que existen otras posibilidades" (Bruna, comunicación personal, 30.09.2019). Bruna trabaja como voluntaria en un preuniversitario comunitario y lo hace con la convicción de que, si hay confianza en los estudiantes, ellos podrán transformar su futuro. Ella manifestó sentirse satisfecha de que algunos de sus alumnos consiguieron ingresar a la universidad pública. Cuidar implica sostener la esperanza crítica de que otros futuros son posibles ${ }^{9}$.

Como quinto rasgo, encontramos en su práctica una lucha por desestigmatizar a los estudiantes. La misma docente declaró que hay mucha represión sobre los jóvenes negros de la periferia y que trabajar con ellos le ha permitido deconstruir esa frase inhumana que repiten los medios de comunicación: "que un bandido bueno era un bandido muerto" (Bruna, comunicación personal, 30.09.2019). Trabajar por la

9. Los cursinhos populares, como en el que Bruna hace su voluntariado, proliferan en las favelas de Rio de Janeiro como una estrategia de activismo que busca preparar a los jóvenes de la periferia para que obtengan buenos resultados en las pruebas de Estado para ingresar a la educación superior. Este tipo de cursinhos han sido fundamentales para esquivar los filtros clasistas, racistas y meritocráticos que conforman el sistema de ingreso a la universidad pública en Brasil. 
educación ha significado defender el honor de sus estudiantes y desafiar, incluso de manera directa, a los agentes policiales.

Ya tuve una situación así de protección, de ver a un alumno siendo abordado por un policía en la puerta de la escuela. Yo dije: “¡Opa! Buenas tardes. ¿Qué es lo que está pasando?”. Y aquella cosa de mostrar que él era un alumno, que él estudia aquí, que lo conozco, que es alumno frecuente. (Bruna, comunicación personal, 30.09.2019)

Por último, uno de los hallazgos que tuvimos en el trabajo de campo es que las profesoras producen estrategias pedagógicas y didácticas para abordar las emociones $y$ los dolores producidos por los impactos de la violencia armada. A nuestro modo de ver, estas experiencias pedagógicas posibilitan una lectura del contexto utilizando la reflexión sobre las emociones, el arte y la poesía, para provocar un pensamiento crítico sobre la violencia y producir transformaciones en el entorno escolar.

La profesora Aline, que trabaja en educación infantil en una escuela ubicada en las favelas del barrio Santa Teresa, desplegó una metodología llamada diccionario poético del cuerpo para conversar con los niños sobre su vida cotidiana. Por medio de dibujos y narraciones, van aprendiendo las vocales e identificando saberes cotidianos, experiencias, gustos, sufrimientos. La profesora Aline plantea un ejercicio para hablar del cuerpo como un lugar de inscripción de memorias y afectos: con los niños va identificando emociones como la alegría, el enojo o el miedo. Juntos escriben un diccionario para darle significado a sus sentimientos y para sanar por medio de narraciones poéticas.

Te voy a compartir un fragmento del diccionario. La palabra miedo. Los niños escribieron: "el miedo vive dentro de nuestro corazón"; "la muñeca Anabelle me da miedo"; otro dijo que le daba miedo el payaso asesino; "a mí me da miedo el fantasma de la mujer en el espejo"; "a mí me da miedo ahogarme en la playa”; otro niño dijo que le daba miedo el tiroteo de la policía; otro dijo que los zombis, las momias, los dragones (...). Tú ves que los niños sacan cosas serias como el asunto de la policía, entonces, con el diccionario he conseguido hablar sobre el cuerpo, sobre las emociones. Fue una forma de pensar juntos y de elaborar eso para que ellos hablen lo que están sintiendo y ver cómo puedo ayudarlos. (Aline, comunicación personal, 29.04.202O)

\section{A modo de cierre}

¿Qué pueden hacer las escuelas y los docentes, en un contexto de violencia armada, para mitigar los efectos devastadores del exterminio y el racismo? En este recorrido por la experiencia docente de profesoras negras que enseñan en las favelas de 
Rio de Janeiro, encontramos que una praxis del cuidado y un trabajo emocional se convierten en respuestas concretas para atender el daño, la destrucción y la muerte que ocasionan las dinámicas de la violencia armada.

Si bien una práctica educativa comprometida con el cuidado no repara por sí sola los daños que genera la estructura de violencia, sí reside en ella una potencia, una capacidad de germinar la vida como si se tratara de una pequeña planta que crece agrietando un pesado asfalto. Es en la visceralidad de la vida cotidiana y en una implicación con los mundos en los que viven los estudiantes, donde residen posibilidades para la transformación de los entornos escolares.

Aquí retomamos la idea de Mbembe (2019) de concebir la política como un ejercicio que involucra los órganos, el corazón, los intestinos; una visceralidad que está configurada por tramas íntimas de dolor, sufrimiento, enojo, indignación y miedo. La pedagogía visceral retoma los motivos del cuerpo y establece una resonancia emocional con el dolor de los otros; abre espacios para tocar la historia de cuerpos que han sido humillados, perseguidos y exterminados. Es una pedagogía que apunta a entender que la vulnerabilidad de los cuerpos merece ser reconocida y que, a partir de esa disposición, de ese pensar-con el otro, se pueden proyectar formas para desnaturalizar la violencia, escuchar los traumas, sanar, curar y cuidarse de alguna manera.

Las docentes de Rio de Janeiro evidencian que no se trata de una praxis de cuidado inocente; no es un cuidado que nace de una supuesta esencia femenina, sino de una ética política localizada en los márgenes, no es un ejercicio sentimental ni asistencial ni caritativo. El cuidado que se pone en marcha para defender la vida en las escuelas es un cuidado disruptivo, porque entiende que educar no se reduce a la cognición y la disciplina, sino a la búsqueda de un bienestar espiritual, físico y emocional. Esta es una educación que aboga por la sanación y por la reparación de los tejidos colectivos que ha roto la violencia.

La propuesta que dimana de las maestras negras cariocas plantea que una pedagogía crítica de la violencia debe pasar por el cuestionamiento de las rutinas y las normas escolares, romper con el silencio que impone el racismo y tejer conexiones afectivas para que los estudiantes construyan una autoestima sana que les permita reescribir su historia y resistir la dominación.

Las profesoras que agencian esta postura pedagógica en las favelas no son ángeles, sino sujetos carnales que construyen parentescos políticos en condiciones de explotación, incertidumbre y falibilidad. Sus experiencias laborales revelan cómo las políticas de exterminio de la población negra en Brasil modifican la vida de las escuelas y colocan pesadas cargas de cuidado sobre las mujeres, quienes intentan paliar una situación límite que es producida por la ausencia social del Estado y por escuelas poco comprometidas con la eliminación del racismo. 
La juventud negra y sus comunidades han resistido con potencia a las políticas de exterminio que ejecutan los agentes armados del Estado, así como las facciones criminales y el narcotráfico (Gomes; Laborne, 2018). Ellos exigen que se garantice su derecho a la vida. Es preciso que se repare con justica la discriminación histórica que han vivido las personas negras, y esto implica una redistribución material, pero también una sanación interna de los daños emocionales que generan el racismo y la exclusión. Las escuelas y los docentes pueden aportar en esta tarea, toda vez que persistan en cuestionar constantemente las normas de raza, género y clase que oprimen y matan.

La escuela puede ayudar a mover pedagogías del cuidado en la medida en que no se quede atada a una simple empatía con el sufrimiento de los estudiantes, sino que transforme el dolor en acción y el silencio en palabra, con el fin de reclamar una posibilidad para que los cuerpos negros dejen de cargar con las marcas del color del miedo (Gomes; Laborne, 2018). Creemos que la escuela puede contribuir con la reparación si produce relaciones comprometidas con el trabajo y la ética del cuidado, y el sostenimiento de la vida. Esto sucederá solo si la institución escolar lucha contra la crueldad de las violencias del capitalismo, el racismo y el sexismo; y si trabaja la consciencia de que solamente un mundo vincular y comunitario pone límites a la expropiación de la vida.

\section{Referencias}

2018: 342 tiroteios/disparos de arma no grande rio foram próximos à escolas (18 de enero de 2019). Fogo Cruzado. Recuperado de https://fogocruzado.org.br/342-tiroteios-disparosde-arma-de-fogo-no-rio-foram-proximos-de-escolas-em-2018/

Arango, Luz Gabriela (2018). Cuidados, trabajo emocional y corporal en los servicios estéticos. En Género, trabajo y cuidado en salones de belleza (pp. 115-143), editado por Luz Gabriela Arango; Javier Pineda. Bogotá: Universidad Nacional de Colombia.

Biroli, Flávia; Miguel; Luis Felipe (2015). Gênero, raça, classe. Opressões cruzadas e convergências na reprodução das desigualdades. Mediações, 20(2), 27-55. http://dx.doi. org/10.5433/2176-6665.2015v20n2p27

Burgos, Marcelo (2009). Escola e projetos sociais: uma análise do 'efeito-favela'. En A escola e a Favela (pp. 59-131), compilado por Marcelo Burgos; Angela Paiva. Rio de Janeiro: PUC Rio.

Carvalho, Marília (1999). No coração da sala de aula: gênero e trabalho docente nas séries iniciais. São Paulo: Xamã/Fapesp. 
Carvalho, Marília; Oliveira, Ivana; Modesto, Ângela; Silva Neto, Cláudio (2020). As professoras e a nova gestão pública: entre o cuidado e as metas. En Gênero e educação: 20 anos construindo conhecimento (pp. 197-232), coordinado por Cláudia Vianna; Marília de Carvalho. São Paulo: Grupo Autêntica.

Catini, Carolina (2019). Privatização da educação e gestão da barbárie. En Educação contra a barbárie (pp. 100-124), compilado por Fernando Cássio. São Paulo: Boitempo.

Cerqueira, Daniel; Lima, Renato de; Bueno, Samira (2017). Atlas da violência 2017. Rio de Janeiro: IPEA/FBSP.

Ciervo, Tassia; Silva, Roberto (2019). A centralidade das competências socioemocionais nas políticas curriculares contemporâneas no Brasil. Revista e-Curriculum, 17(2), 382-401. http://dx.doi.org/10.23925/1809-3876.2019v17i2p382-401

Collins, Patricia H. (2019). Pensamento feminista negro. São Paulo: Boitempo.

Farias, Juliana (2007). Quando a exceção vira a regra: os favelados como população matável e sua luta por sobrevivência. Teoria \& Sociedade, 15(2), 138-171.

Fisher, Berenice; Tronto, Joan (1990). Toward a Feminist Theory of Caring. En Circles of Care: Work and Identity in Women's Lives (pp. 35-62), editado por Emily K. Abel; Margaret K. Nelson. Nueva York: State University of New York.

GloboNews; RJTV (26 de junio de 2017). PM é indiciado pela morte da estudante Maria Eduarda no Rio. G1. Recuperado de https://g1.globo.com/rio-de-janeiro/noticia/pm-e-indiciadopela-morte-da-estudante-maria-eduarda-no-rio.ghtml

Gomes, Nilma Lino; Laborne, Ana Amélia de Paula (2018). Pedagogia da crueldade: racismo e extermínio da juventude negra. Educação em Revista, 34, 1-26. http://dx.doi. org/10.1590/0102-4698197406

Gonzalez, Lélia (1983). Racismo e sexismo na cultura brasileira. En Movimentos sociais urbanos, minorias étnicas e outros estudos (pp. 223-244), editado por Luiz Antônio Silva Machado. Brasília: ANPOCS.

Haraway, Donna (2019). Seguir con el problema. Generar parentesco en el Chthuluceno. Bilbao: Consonni.

Henry, Annette (2011). Feminist Theories in Education. En Handbook of Research in the School Foundations of Education (pp. 261-282), editado por Stiven Tozer; Bernardo Gallegos. New York: Routledge.

Hirata, Helena; Guimarães, Nadya; Sugita, Kurumi (2012). Cuidado e cuidadoras: o trabalho do care no Brasil, França e Japão. En Cuidado e cuidadoras. As várias faces do trabalho do care (pp. 79-12), coordinado por Helena Hirata; Nadya Guimarães. São Paulo: Atlas. 
Hochschild, Arlie (1979). Emotion Work, Feeling Rules, and Social Structure. American Journal of Sociology, 85(3), 551-575. Recuperado de http://www.jstor.org/stable/2778583

hooks, bell (2003). Rock my Soul. Black People and Self-Esteem. New York: Ateria Books.

hooks, bell (2010). Teaching Critical Thinking. Practical Wisdom. New York: Routledge.

Isenbarger, Lynn; Zembylas, Michalinos (2006). The Emotional Labor of Caring in Teaching. Teaching and Teacher Education, 22, 120-124. Recuperado de https://www.academia. edu/16642465/The_emotional_labour_of_caring_in_teaching

Kergoat, Danièlle (2016). O cuidado e as imbricações das relações sociais. En Gênero e trabalho no Brasil e na França: perspectivas interseccionais (pp. 17-26), coordinado por Alice de Paiva Abreu; Helena Hirata; Maria Lombardi. São Paulo: Boitempo.

Larrosa, Jorge (2019). Esperando não se sabe o quê. Sobre o oficio de professor. São Paulo: Autêntica.

Machado da Silva, Luiz; Leite, Márcia (2015). Circulação e fronteiras no Rio de Janeiro: a experiência urbana de jovens moradores de favelas em contexto de "pacificação". En Sobre a periferia. Novos conflitos no Brasil Contemporâneo (pp. 146-158), coordinado por Neiva Da Cunha; Gabriel Feltran. Rio de Janeiro: FAPERJ/Lamparina.

Mbembe, Achile (2019). Necropolitics. Durham: Duke University Press.

Muniz, Rosana (2019). Os caminhos da aprendizagem no Complexo do Chapadão (Tesis de maestria). Postgrado em Educação, Cultura e Comunicação em Periferias Urbanas, Facultad de Educación de la Baixada Fluminense, Universidade do Estado do Rio de Janeiro, Rio de Janeiro, Brasil.

Murillo, Javier; Hernández, Reyes (2014). Liderando escuelas justas para la justicia social. Revista internacional de educación para la justicia social, 3(2), 13-32. Recuperado de https:// revistas.uam.es/riejs/article/view/337

Oliveira, João (2014). Pacificação e tutela militar na gestão de populações e territórios. Mana, 2O(1), 125-161. https://doi.org/10.1590/S0104-93132014000100005

Plataforma DhESCA Brasil (2008). Violação aos direitos educativos da comunidade do Complexo do Alemão (Rio de Janeiro). Rio de Janeiro: Plataforma Dhesca Brasil.

Puig de la Bellacasa, Maria (2012). 'Nothing Comes without its World': Thinking with Care. The Sociological Review, 60(2), 197-216. https://doi.org/10.1111/j.1467-954X.2012.02070.x

Quintero, Marieta; Sánchez, Keilyn; Ballesteros, Nine (2019). Pedagogía para la paz territorial. Geopolítica de las emociones en tramas narrativas de maestrosy maestras. Bogotá: Universidad Distrital Francisco José de Caldas.

Rancière, Jacques (2004). O mestre ignorante. Cinco lições sobre a emancipação intelectual. São Paulo: Autêntica. 
Rebughini, Paola (1998). Comparação qualitativa de objetos complexos e os efeitos da reflexibilidade. En Por uma sociologia reflexiva. Pesquisa qualitativa e cultura (pp. 204-226), compilado por Alberto Melucci. Milán: Prismi.

Rede de Observatórios da Segurança (2020). A cor da violência policial: a bala não erra o alvo. Rio de Janeiro: CESEC.

Segato, Rita (2018). Contra-pedagogías de la crueldad. Buenos Aires: Prometeo.

Silva, Roberto (2017). Emocionalização, algoritimização e personalização dos itinerários formativos: como operam os dispositivos de customização curricular? Currículo sem fronteiras, 17(3), 699-717.

Sorj, Bila (2016). Políticas sociais, participação comunitária e a desprofissionalização do care. Cadernos Pagu, 46, 107-128. https://doi.org/10.1590/18094449201600460107

Veillette, Anne-Marie; Nunes, Nilza de Andrade (2017). As mulheres e os efeitos da pacificação das favelas no Rio de Janeiro: compreendendo o gênero na política de segurança. O social em questão, 38, 171-190. Recuperado de http://osocialemquestao.ser.puc-rio.br/media/ OSQ_38_art_9_Veillette_Nunes.pdf

Zembylas, Michalinos (2007). The Power and Politics of Emotions in Teaching. En Emotion in Education (pp. 293-312), compilado por Paul Schutz; Reinhard Pekrun. Boston: Elsevier. 